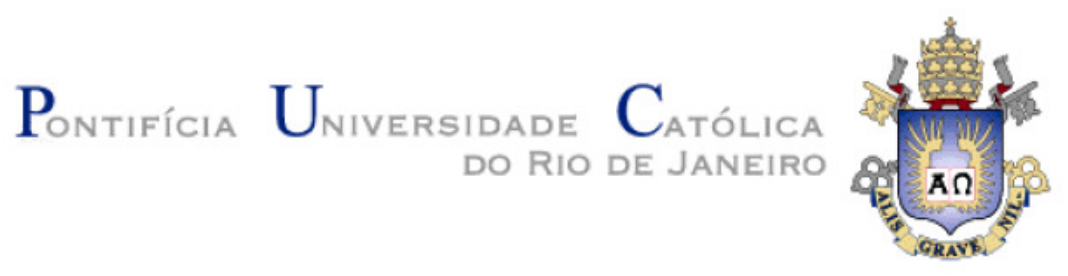

Maurício Marcos Otaviano

Fósforo Auto Fluxado em Pelotas Para Redução Direta

Tese de Doutorado

Tese apresentada como requisito parcial para obtenção do título de Doutor pelo Programa de Pós-Graduação em Engenharia e Processos Químicos e Metalúrgicos da PUC-Rio.

Orientador: Prof. José Carlos D’Abreu 


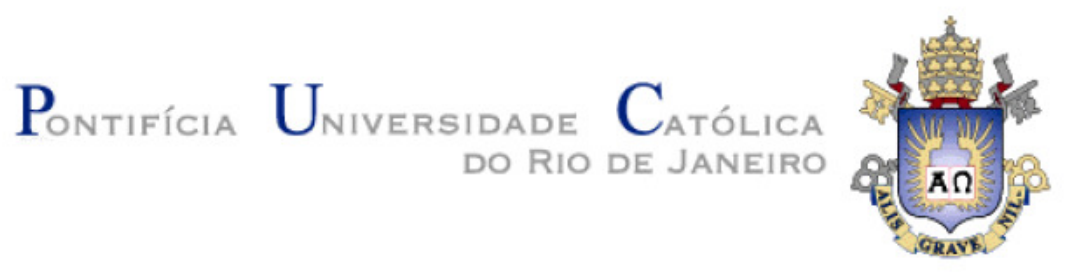

Maurício Marcos Otaviano

\section{Fósforo Auto Fluxado em Pelotas Para Redução Direta}

Tese apresentada como requisito parcial para obtenção do título de Doutor pelo Programa de Pós-Graduação em Engenharia de Materiais e Processos Químicos e Metalúrgicos da PUC-Rio. Aprovada pela Comissão Examinadora abaixo assinada.

Prof. José Carlos D’Abreu Orientador Departamento de Engenharia dos Materiais - PUC - Rio

PhD. Hélio Marques Kohler Techn'os

Prof. Francisco José Moura Departamento de Engenharia dos Materiais - PUC - Rio

Prof. Roberto José Carvalho Departamento de Engenharia dos Materiais - PUC - Rio

Dr. Junia Maria Pinho Rocha Samarco Mineração S.A

Dr. Denílson Rodrigues de Araújo Samarco Mineração S.A.

Prof. José Eugenio Leal Coordenador Setorial do Centro Técnico Científico - PUC-Rio 
Todos os direitos reservados. E proibida a reprodução total ou parcial do trabalho sem autorização da universidade, do autor e do orientador.

\section{Maurício Marcos Otaviano}

Graduou-se em Engenharia Metalúrgica pela Universidade Federal de Ouro Preto - UFOP, em 1992. Trabalha na Empresa Samarco Mineração S.A. desde 1992, onde se desempenha a função de Especialista Sênior de Produtos.

Ficha Catalográfica

Otaviano, Maurício Marcos

Fósforo auto fluxado em pelotas para redução direta / Maurício Marcos Otaviano; orientador: José Carlos D'Abreu. - 2012. 239 f. : il. (color.) ; $30 \mathrm{~cm}$

Tese (doutorado)-Pontifícia Universidade Católica do Rio de Janeiro, Departamento de Engenharia de Materiais, 2012.

Inclui bibliografia

1. Engenharia de materiais - Teses. 2. Minério supergênicos. 2. Redução direta. 3. Fósforo. 4. Processo de endurecimento. 5. Forno elétrico a arco. 6. Fluxagem I. D'Abreu, José Carlos. II. Pontifícia Universidade Católica do Rio de Janeiro. Departamento de Engenharia de Materiais. III. Título.

CDD: 620.11 
Agradeço a minha família, ao meu pai in memória, a minha querida Mãe por terem sido os meus grandes incentivadores.

À minha Esposa e Filhos pelo amor e carinho. Agradeço a Deus por ser meu suporte em todos os momentos. 


\section{Agradecimentos}

Agradeço a toda a Diretoria da Samarco Mineração S/A por estimular a continuidade dos programas de pós-graduação de seus empregados. À Gerência Geral de Marketing e Vendas pelo estímulo à busca de soluções inovadoras aos desafios tecnológicos para a aplicação dos produtos da Samarco.

Aos companheiros da Gerência de Assistência Técnica pelo apoio e incentivo nas diversas discussões técnicas sobre o tema e aos técnicos e engenheiros da Gerência de Automação e Processo por terem viabilizado todos os ensaios de análises químicas e metalúrgicas necessário para o desenvolvimento deste trabalho.

Agradeço ao Prof. Dr. José Carlos D’Abreu pelos valiosos ensinamentos sobre a arte da metalurgia, organização e estruturação de uma pesquisa científica e efetiva orientação deste trabalho.

Ao Prof. Dr. Hélio Marques Kohler pelo apoio, orientações e fundamental participação nas modelagens matemáticas e estatísticas apresentadas neste trabalho. E por compartilhar sua imensa cultura geral em nossas conversas.

Agradeço ao Engenheiro MSc Hélio Cardoso Pereira por não ter medido esforços em liberar-me do trabalho para viagens à PUC-Rio, enquanto responsável pela Gerência de Assistência Técnica. 
Ao Engenheiro MSc Flávio Lopes, Gerente da Assistência Técnica, pelo incentivo e apoio fundamentais para a conclusão deste longo período de aprendizado e desenvolvimento.

Agradeço ao Engenheiro MSc Augusto Mendonça Lessa pelo companheirismo durante do curso das disciplinas acadêmica da PUC-RIO, incentivo e preciosa ajuda profissional em nossas longas rotinas de viagens pelo mundo. Sincera amizade demonstrada nos 5 anos que trabalhamos juntos.

Agradeço ao Dr. Denílson Rodrigues Araújo por incentivar a participar do programa de doutorado, pela sugestão do tema desenvolvido e por aceitar prontamente o convite para a banca examinadora.

Agradeço ao engenheiro Edelink Efrain Tinoco Falero pela importante contribuição à frente do trabalho de mestrado, o qual concluiu em 2011, sobre o Comportamento do Fósforo no Pellet Feed e nas Escórias Sintéticas das Pelotas RD. Pelo envolvimento e disponibilidade em todas as fases deste trabalho, pela valorosa amizade desenvolvida com minha família.

Ao Técnico de controle de processo Anderson Pedruzzi e Renato Zucolotto pela inestimável participação no desenvolvimento das metodologias de análise química.

Agradeço às técnicas do laboratório de microscopia óptica Heidy Oliveira Ferreira e Ana Maria Guilherme pela dedicação e senso de qualidade nos preparos das amostras para a microscopia eletrônica e desenvolvimento das análises microscopia ópticas.

Agradeço a toda a equipe do laboratório metalúrgico, em especial, aos laboratoristas Sanderson Dattestim Bernades e Alaércio Meschiatti, pelo grande suporte e pró-atividade na realização dos experimentos laboratoriais.

À Equipe do Pot Grate Vinícius Perim, Alexandre Juvenal Anacleto, João Luis Moreira e Gleidson Martins dos Santos pelo profissionalismo e excelência técnica na condução dos testes de endurecimento das pelotas produzidas nos projetos de experimentos. 
Agradeço ao Engenheiro Thiago Marchezi Doellinger que, como chefe de equipe dos laboratórios de pesquisa, não mediu esforços para viabilizar os ensaios laboratoriais.

Agradeço à Tatiana Silva e Silva e Simone Theodoro Lima pelo apoio na programação das viagens para o RJ, bem como no suporte às respectivas prestações de contas e gerenciamento dos aditivos firmados pelo convênio.

Agradeço aos meus pais por me ensinar os valores sociais da família e pelo investimento na minha educação fundamental para a minha vida profissional.

Agradeço à Manuela Pompermayer Farias pela organização, dedicação e qualidade para estruturação deste trabalho. A quem desejo pleno sucesso em sua nova carreira como engenheira metalurgista.

Agradeço a minha querida esposa Ana Maria por ter pacientemente suportado minhas ausências mantendo a harmonia de minha família.

Aos meus filhos Marina e Vitor por me proporcionar um novo ciclo de aprendizado e motivação para contornar adversidades da minha vida, pessoal e profissional.

Agradeço a todas as demais pessoas que, direta ou indiretamente, deram alguma contribuição neste trabalho, demonstrando mais uma vez que na vida ninguém faz nada sozinho.

Agradeço a Deus pela fonte inesgotável de energia que tem me ajudado nesta longa caminhada de aprendizados. Foram incontáveis horas de estudos e muitas vezes nas longas jornadas de avião nas inúmeras viagens a trabalho pelo mundo. Abdicar da oportunidade de lazer com os filhos e esposa não foi fácil. Porém a vontade de contribuir de forma significativa para o conhecimento dos fundamentos da engenharia metalúrgica me incentivou a continuar. 


\section{Resumo}

Otaviano, Maurício Marcos; D’Abreu, José Carlos. Fósforo Auto Fluxado em Pelotas Para Redução Direta. Rio de Janeiro, 2012. 239p. Tese de Doutorado - Departamento de Engenharia de Materiais, Pontifícia Universidade Católica do Rio de Janeiro.

As jazidas mundiais de minérios de ferro tendem ao empobrecimento dos teores de ferro, aumento das gangas (sílica, alumina, fósforo, etc.) e maiores ocorrências de minérios hidratados. Esta mudança vem gerando um esforço no sentido de aprimorar as técnicas de extração e beneficiamento. O fósforo é um contaminante que em certos teores provoca a fragilização dos aços, sendo, portanto, restritivo ao aproveitamento de importantes jazidas minerais, principalmente as ricas em minérios de origens intempéricas ou supergênicas. Vários trabalhos foram e estão sendo conduzidos visando desenvolver tecnologias capazes de reduzir 0 teor de $\mathrm{P}$ durante 0 processo de beneficiamento. Porém, até 0 momento não têm mostrado viabilidade econômica, face à escala de produção e a efeitos danosos ao ambiente. No caso da Samarco, os minérios foram gerados principalmente por processos de enriquecimento supergênico, nos quais é comum a presença de considerável goethita, que é apontada como principal mineral portador do fósforo. O objetivo deste trabalho foi, de forma original, a formulação de uma pelota para redução direta de forma que o fósforo se encontrasse fluxado em fases escorificadas. Essas fases, produzidas através de um adequado ciclo térmico de endurecimento e com composição química otimizada, resultaria em pelotas onde este elemento se mantivesse estável, tanto na produção do DRI quanto na fusão e refino oxidante deste no FEA. Para tanto foram realizados, além de uma ampla revisão bibliográfica, concebido um procedimento analítico original para quantificação apenas do fósforo liberado; planejado experimentos para: a avaliação cinética da migração deste fósforo em pellet feed, nas pelotas e no DRI quando submetido a diferentes aportes térmicos e auto-fluxagens; analise da influência das variáveis do processo de endurecimento sobre a liberação do fósforo e sua escorificação; e comprovação da estabilidade das fases 
escorificadas durante a redução, em escala de laboratório, e durante a fusão e refino conduzido em um FEA semi-industrial. Os resultados obtidos mostraram ser viável a produção de pelotas para redução direta com o fósforo auto-fluxado em fases estáveis.

\section{Palavras-chave}

Minério supergênicos; redução direta; fósforo; processo de endurecimento; forno elétrico a Arco; fluxagem. 


\section{Abstract}

Otaviano, Mauricio Marcos; D’Abreu, José Carlos (Advisor). Phosphorus

Self-Fluxed in Direct Reduction Pellets. Rio de Janeiro, 2012. 239p. Doctorate Thesis - Departamento de Engenharia de Materiais, Pontifícia Universidade Católica do Rio de Janeiro.

Actually the iron ore deposits in the world have the tendency to decrease the iron content, increasing the gangue (silica, alumina, phosphorus, etc.) and to further occurrence of hydrated ores. This change demands improvements in concentration processing techniques for feasible mining operations. The phosphorus is a contaminant that, in some contents, causes the embrittlement of steels, been, wherefore, a limitative to the use of important ore deposits, mostly regarding the weathered iron ores or supergene origins. Several studies were and have been conducted aiming to develop technologies capable of decreasing the $\mathrm{P}$ content during the beneficiation process. However, until now, the economic viability of such studies has not been feasible, considering the production scale and the harmful effects to the environment. In Samarco's case, the mine geological formation is mostly supergene, which is responsible for the presence of the goethite ores, pointed as the main phosphorus carrier. The main point of this work was, with an innovating approach, formulate a new type of pellet addressed to direct reduction processes in a manner that the $\mathrm{P}$ could be fluxed into the slag phases. These phases, produced through an adequate thermal cycle of induration and with an optimized chemical composition, resulted in pellets with stable slags containing, as well as in the produced DRI and in the melted bath generated during the primary refining performed in the EAF. For this purpose, it was done, further to a wide bibliographic review, an original analytical procedure to quantify the released phosphorus and a series of planned experiments, such as: the kinetic evaluation of the phosphorus migration from the mineral phases of the pellet feed when subjected to different thermal treatments; analysis of the induration process variables which could affect the phosphorus release and its fluxing into the slag ; Finally, the stability of the fluxing phases during the reduction in a laboratory scale and the melting and refining 
process in a semi-industrial EAF, were performed. The obtained results showed the feasibility of this new approach produce DR pellets with self-fluxed phosphorus trapped in stable phases.

\section{Keywords}

Supergene iron ore; direct reduction; phosphorus; indurating process; electric arc furnace; flux. 


\section{Sumário}

1 Introdução 28

2 Relevâncias e Objetivos $\quad 29$

2.1. Relevâncias 29

2.2. Objetivos 31

3 Revisão Bibliográfica 32

3.1. Efeito do Fósforo nos Aços 32

3.1.1. Resistência 32

3.1.2. Ductilidade 34

3.1.3. Fenômenos de Fragilização 35

3.2. Ocorrências do Fósforo nos Minérios de Ferro 36

3.3. Samarco Mineração S. A. - Processo Produtivo 40

3.3.1. Operações de Mina 40

3.3.2. Processo de Concentração $\quad 40$

3.3.3. Processo Samarco de Pelotização de Minério de Ferro 41

3.3.4. Especificação da Pelota 50

3.4. Elementos Residuais 51

3.5. Tentativas para Redução do Teor de Fósforo de Minérios Itabiríticos do Complexo de Alegria 52

3.6. Desfosforação nas Rotas de Produção do Ferro Primário 54

3.6.1. Alto-forno 54

3.6.2. Processos de Redução Direta 58

3.6.3. Desfosforação na Rota Alto-forno - Conversores a Oxigênio BOF/LD 66

3.6.4. Desfosforação na Rota DR - EAF 72

4 Metodologia $\quad 89$

5 Investigações Preliminares $\quad 90$

5.1. Procedimento Experimental 90

5.1.1. Caracterização da Ocorrência do Fósforo no Pellet Feed e Fases Escorificadas das Pelotas PRDMX 90

5.1.2. Resultados das Investigações Preliminares 93

6 Conclusões Preliminares 105

7 Etapas para o Desenvolvimento do Estudo da Auto-fluxagem do Fósforo em Pelotas de Redução Direta 106 
7.1. Desenvolvimento de uma Metodologia para Quantificar a Liberação do Fósforo das Diversas Fases Mineralógicas Durante os Ciclos Térmicos do Processamento das Pelotas Queimadas

7.1.1. Etapas para o Desenvolvimento de um Procedimento Experimental de Dissolução Seletiva para Quantificação da Liberação do Fósforo

7.2. Avaliação da Natureza Morfológica das Escórias das Pelotas de Redução Direta

7.3. Avaliação da Influência do Efeito da Basicidade Binária, Temperatura

e Tempo sobre o Comportamento do Fósforo Presente nas Fases Minerais do Pellet Feed

7.3.1. Análise dos Resultados da Influência do Efeito da Basicidade

Binária, Temperatura e Tempo sobre o Comportamento do Fósforo

Presente nas Fases Minerais do Pellet Feed

7.3.2. Modelamento Cinético da Decomposição Térmica das Fases

Minerais Portadora do Fósforo no Pellet Feed

7.4. Avaliação da Influência da Temperatura de Endurecimento, Tempo de Residência e Basicidade Binária sobre a Migração do Fósforo para os Compostos Escorificados da Pelota

7.4.1. Delineamento do Projeto de Experimento

7.4.2. Análise dos Resultados do Projeto de Experimento

7.5. Análises Termodinâmicas e Projeto de Experimento para Avaliar a

Estabilidade das Fases Escorificadas, sob as Condições de Redução em um Forno de Redução Direta

7.5.1. Analise Termodinâmica e Confirmação da Estabilidade das Fases Escorificadas sob as condições de redução em um forno tipo Midrex

7.5.2. Projeto de Experimento para Confirmar a Estabilidade das Fases Escorificadas, sob as Condições de Redução de um Forno de Redução Direta

7.5.3. Análise dos Resultados

7.6. Análise do comportamento do fósforo nas fases escorificadas do DRI no processo de fusão e refino em um forno elétrico a arco experimental

7.7. Análise dos resultados obtidos nos experimentos de fusão e refino

8.1. Sugestões para Trabalhos Futuros 208

9 Referências Bibliográficas

ANEXO A - Procedimento para Calibração e Aumento da Precisão da 
Análise do Fósforo no ICP

ANEXO B - Certificados dos Materiais de Referência de Minério de Ferro

Samarco e IPT para a Calibração do ICP

ANEXO C - Perfis Térmicos dos Experimentos Fatoriais para Produção de

Pelotas em Pot grate

223

ANEXO D - Análise fatorial do projeto de experimentos

227

ANEXO E - Dados de liberação do fósforo obtidos através do

modelamento dos dados experimentais.

ANEXO F - Análise Estatística e Parâmetros das Equações Quadráticas

do Projeto Experimento

ANEXO G - Determinação dos erros obtidos no modelamento dos dados experimentais

ANEXO $\mathrm{H}$ - Corridas realizadas em um forno elétrico experimental

ANEXO I - Determinação da variação do poder redutor dos gases de

processo ao longo da zona de redução de um reator Midrex 


\section{Lista de figuras}

Figura 1 - Tendência de crescimento da produção mundial de aço bruto ${ }^{(2)}$. 29

Figura 2 - Tendência de crescimento da produção mundial de pelotas da Rota Redução Direta ${ }^{(2)}$.

Figura 3 - Tendência de crescimento da produção mundial de pelotas da Rota Alto-Forno ${ }^{(2)}$.

Figura 4 - Mudança na tensão de escoamento inferior do aço carbono em função da adição de liga de vários elementos comuns ${ }^{(4)}$.

Figura 5 - Variação do Limite de escoamento do aço carbono em função da adição de liga de vários elementos comuns ${ }^{(5)}$.

Figura 6 - relação entre a diminuição no alongamento e o aumento da resistência a tração resultante de adições de $\mathrm{P}, \mathrm{Mn}$ e $\mathrm{Si}^{(4)}$.

Figura 7 - Formação Mineralógica e Microestrutural de Minérios de Ferro para Pelotização ${ }^{(7)}$.

Figura 8 - Esquema do processo de precipitação de fósforo LER e STANFORTH (apud 11).

Figura 9 - O disco de pelotamento e seu princípio de funcionamento ARAÚJO (apud 1).

Figura 10 - Forno de pelotização ${ }^{(1)}$.

Figura 11 - Perfil térmico ilustrativo de um ciclo de endurecimento obtido em pot grate para simulação de processos industriais.

Figura 12 - Formação de fases escorificadas e recristalização intergranuladas ${ }^{(14)}$.

Figura 13 - Diagrama ternário do sistema CaO-Fe2O3-SiO2 MUAN (apud 15).

Figura 14 - Diagrama binário do sistema CaO-SiO2 MUAN (apud 15).

Figura 15 - Teor de Elementos Residuais contidos na Pelota ${ }^{(19)}$.

Figura 16 - Teor de fósforo nas pelotas de vários fornecedores ${ }^{(19)}$.

Figura 17 - Rotas de fabricação do aço ${ }^{(22)}$.

Figura 18 - Alto-forno a esquerda detalhes da distribuição de cargas no interior do forno e suas diversas zonas, a direita perfil de temperaturas ao longo do alto-forno, típicas regiões de predominância dos diversos estágios da redução dos óxidos, decomposição de carbonatos, escorificação e fusão do ferro reduzido ${ }^{(7)}$. 
Figura 19 - Fluxograma Processo Midrex ${ }^{(24)}$.

Figura 20 - Fluxograma do processo HyLIII ${ }^{(22)}$.

Figura 21 - Fluxograma do processo HyL (míni-módulos) com alto-reforma do gás natural ${ }^{(25)}$.

Figura 22 - Ferro-esponja granulado (DRI) e briquetado (HBI), CHELLY (apud 1)

Figura 23 - Diagrama de Ellingham. NOTA: adaptado pelo autor ${ }^{(27)}$.

Figura 24 - Diagrama de oxi-redução dos sistemas Fe-C-H-O ${ }^{(22)}$.

Figura 25 - Evolução do Kp em função da basicidade e da oxidação da escória MARTINS JÚNIOR ${ }^{\text {(apud 23). }}$

Figura 26 - Representação de um processo de refino em um convertedor a oxigênio destacando as reações características do processo, em destaque as reações de oxidação e escorificação do fósforo ${ }^{(29)}$.

Figura 27 - Evolução da composição da composição química do metal em função do tempo de sopro e da descaburação do banho ${ }^{(30)}$.

Figura 28 - Sequência esquemática de operações de um processo de refino oxidante em Conversor LD/BOF ${ }^{(29)}$.

Figura 29 - Partição do Fósforo em função da concentração da basicidade da escória e do $\mathrm{FeO}^{\left({ }^{32}\right)}$.Diagramas empíricos obtidos de dados práticos; temperaturas de processo inferiores a $1833 \mathrm{~K}$.

Figura 30- Desfosforação e Dessulforação simultâneas de gusa baixo e alto silício ${ }^{(33)}$.

Figura 31 - Equações de Partição do Fósforo entre escória e metal ${ }^{(34)}$. 76

Figura 32 - Sequência de uma corrida difusão e refino ${ }^{(35)}$. 77

Figura 33 - Sucata de aço ${ }^{(36)}$. 78

$\begin{array}{ll}\text { Figura } 34 \text { - Sucata de ferro-gusa }{ }^{(36)} & 79\end{array}$

Figura 35 - Sucata de ferro fundido ${ }^{(36)}$. 79

Figura 36 - Produtos pré-reduzidos: ferro esponja DRI e briquete $\mathrm{HBI}{ }^{(37)} . \quad 80$

Figura 37 - Ferro-gusa líquido e ferro-gusa sólido ${ }^{(36)}$. 81

Figura 38 - Operação do carregamento por batelada de um EAF através de cestão ${ }^{(40)}$. 83

Figura 39 - Sistema de alimentação contínua de pré-reduzido em uma aciaria elétrica SCARANATI et al (apud 22).

Figura 40 - Tecnologias de descarga a quente e a frio do processo MIDREX para o EAF. $\mathrm{H}_{2} \mathrm{O}^{(41)}$.

Figura 41 - Tecnologias de descarga a quente e a frio do processo HyLsa 
para o EAF ${ }^{(42)}$.

Figura 42 - Representação esquemática de um forno elétrico a arco em uma etapa intermediária do processo de refino com destaque para as diversas regiões do forno e para algumas das principais reações químicas inerentes a este processo ${ }^{(39)}$.

Figura 43 - Microscópio ótico Zeiss AxioPlan.microscópio Eletrônico de Varredura ZEISS. Modelo DSM 960 (PUC).

Figura 44 - Disco piloto para produção de pelotas cruas.

Figura 45 - Equipamento para simulação do processo de endurecimento de pelotas de minério de ferro - Pot Grate. À direita ciclo térmico, perfis de temperatura em diferentes camadas: superior, intermediária e inferior, de um teste de queima hipotético.

Figura 46 - Amostra de pellet feed campo estendido, espécies mineralógicas 100X.

Figura 47 - Amostra de pellet feed campo estendido, espécies mineralógicas 500X.

Figura 48 - Micrografias das fases mineralógicas do Pellet Feed (1000X).

Figura 49 - Micrografia: Presença de fósforo em inclusões com associação de cálcio, em uma partícula de hematita especular ou especularita.

Figura 50 - Análise química por EDS. Spectrum 1: Presença de fósforo em inclusões com associação de cálcio, em uma partícula de hematita especular ou especularita.

Figura 51 - Micrografia: Grão de martita e agregado de partículas de hematitas e goethitas.

Figura 52 - - Análise química por EDS. Observa-se presença de fósforo na partícula de goethita no Spectrum 1, associado a silício.

Figura 53 - Micrografia: Grão de hematita especular, à esquerda e agregado de partículas de hematitas e goethitas à direita.

Figura 54 - Análise química por EDS. Presença de fósforo no Spectrum 5, provavelmente um agregado de goethita.

Figura 55 - Micrografia: Grão de hematita especular (HE) e hematitas porosas (HP) provenientes da transformação das goethitas e ou martitas.

Figura 56 - Análise química por EDS, onde não foi constatada a presença de fósforo.

Figura 57 - Micrografia (aumento 1000x): Fases sinterizadas compactas e porosas nas "bordas" das pelotas com basicidade 0,6. 
Figura 58 - Análise química por EDS no Spectrum 7: presença discreta de sílica e cálcio.

Figura 59 - Micrografia (aumento 1000x): Fases sinterizadas no "centro" das pelotas com basicidade 0,6.

Figura 60 - Análise química por EDS no Spectrum 1: presença abundante de fases escorificadas com presença de silício, cálcio e fósforo.

Figura 61 - Micrografia (aumento 1000x): sinterizadas na "bordas" das pelotas com basicidade 1,0.

Figura 62 - Análise química por EDS no Spectrum 1: presença de fases escorificadas com presença de silício, cálcio e fósforo.

Figura 63 - Fases sinterizadas porosas proveniente da transformação das goethitas e ou martita e presença de fases compactas provenientes das especularitas. Abundância de fases escorificadas.

Figura 64 - ICP-OES ( Espectrômetro de Emissão Óptica por Plasma de Acoplamento Indutivo) Fabricante: Spectro Analytical Instruments Modelo: CIROS CCD NSérie: 4N / 0040.

Figura 65 - Resultados da dissolução seletiva das gangas da pelota industrial, utilizando o reagente Oxalato de Amônio 0,2 Mol/litro nas seguintes condições: $\mathrm{pH}=3$, Temperatura ambiente e Agitação por centrifugação.

Figura 66 - Resultados da dissolução seletiva das gangas da pelota industrial, utilizando o reagente Oxalato de Amônio 0,2 Mol/litro nas seguintes condições: $\mathrm{pH}=3$, Temperatura ambiente e Agitação por centrifugação.

Figura 67 - Resultados da dissolução seletiva das gangas da pelota industrial, utilizando os reagentes Citrato de sódio 0,3 Mol/litro, Bicarbonato de sódio $1 \mathrm{Mol} /$ itro e Ditionito de sódio nas seguintes condições: Temperatura de $80^{\circ} \mathrm{C}$, Luz ambiente e Agitação por centrifugação.

Figura 68 - Resultados da dissolução seletiva das gangas da pelota industrial, utilizando o reagente (SODA) $\mathrm{NaOH} 5 \mathrm{Mol} /$ itro nas seguintes condições: Luz ambiente, Tempo de exposição de 60 minutos e Agitação por centrifugação.

Figura 69 - Resultados da dissolução seletiva das gangas da pelota industrial, utilizando o reagente (SODA) $\mathrm{NaOH} 5 \mathrm{Mol} /$ litro nas seguintes condições: Luz ambiente, Temperatura de $90^{\circ} \mathrm{C}$ e Agitação por centrifugação. 
Figura 70 - Resultados da dissolução seletiva das gangas da pelota industrial, utilizando o reagente Ácido Nítrico 2,5 Normal nas seguintes condições: Luz ambiente, Temperatura de $50^{\circ} \mathrm{C}$ e Agitação por centrifugação.

Figura 71 - Resultados da dissolução seletiva das gangas da pelota industrial, utilizando o reagente Ácido Nítrico $0,14 \mathrm{Mol} /$ litro nas seguintes condições: Luz ambiente, Temperatura ambiente e Agitação por centrifugação.

Figura 72 - Resultados da dissolução seletiva das gangas da pelota industrial, utilizando o reagente Acetato do Sódio/Tamponado com Ac. Acético nas seguintes condições: $\mathrm{pH}=4$, Luz ambiente, Temperatura ambiente e Agitação por centrifugação.

Figura 73 - Resultados da dissolução seletiva das gangas da pelota industrial, utilizando o reagente $\mathrm{MgCl}_{2}$ nas seguintes condições: $\mathrm{pH}=8$, Luz ambiente, Temperatura ambiente e Agitação por centrifugação.

Figura 74 - Resultados da dissolução seletiva das gangas da pelota industrial, utilizando o reagente Soda, $\mathrm{NaOH} 5 \mathrm{Mol} /$ litro nas seguintes condições: Luz ambiente, Temperatura ambiente e Agitação por centrifugação. Amostras moídas em diferentes granulometrias.

Figura 75 - Resultados da dissolução seletiva das gangas da pelota industrial, utilizando o reagente Ácido Nítrico,2,5Mol/litro nas seguintes condições: Luz ambiente, Temperatura ambiente e Agitação por centrifugação. Amostras moídas em diferentes granulometrias

Figura 76 - Resultados da dissolução sequencial seletiva das gangas da pelota industrial, utilizando os reagentes: (SODA) $\mathrm{NaOH} 5 \mathrm{Mol} /$ litro e Ácido Nítrico 2,5 Normal.

Figura 77 - Resultados da dissolução sequencial seletiva das gangas da pelota industrial, utilizando os reagentes: Ácido Nítrico 2,5 Normal e (SODA) $\mathrm{NaOH} 5 \mathrm{Mol} /$ litro.

Figura 78 - Resultados da dissolução sequencial seletiva das gangas da pelota industrial, utilizando os reagentes: Ácido Nítrico 2,5 Normal e (SODA) $\mathrm{NaOH} 5 \mathrm{Mol} /$ litro.

Figura 79 - Resultados da dissolução sequencial seletiva das gangas da pelota industrial, utilizando os reagentes: (SODA) $\mathrm{NaOH} 5 \mathrm{Mol} /$ litro e Ácido Nítrico 2,5 Normal.

Figura 80 - Análise do difratograma evidenciando a cristalinidade dos 
componentes da mistura da pelota sintética.

Figura 81 - Panela do pot grate e cadinho na camada inferior do pot grate.

Figura 82 - Cadinho de inox e detalhe da tampa com orifício para introduzir termopar.

Figura 83 - Micrografia X500: Pelota sintética para redução direta.

Figura 84 - Resultados da dissolução sequencial seletiva das gangas da pelota sintética, utilizando os reagentes (SODA) $\mathrm{NaOH} 5 \mathrm{Mol} /$ litro.

Figura 85 - Resultados da dissolução sequencial seletiva das gangas da pelota industrial, utilizando os reagentes (SODA) $\mathrm{NaOH} 5 \mathrm{Mol} /$ litro e Ácido Nitrico 2,5.

Figura 86 - Resultados da dissolução sequencial seletiva das gangas da pelota sintética, utilizando os reagentes (SODA) $\mathrm{NaOH} 5 \mathrm{Mol} /$ litro e Ácido Nítrico 2,5.

Figura 87 - Forno elétrico de mufla (Combustol).

Figura 88 - Perfil térmico no pot grate para o tratamento das escórias sintéticas.

Figura 89 - Difratograma da mistura para produção da escória sintética. 133

Figura 90 - Difratograma da escória sintética formada no pot grate.

Figura 91 - Difratograma da escória sintética formada no forno de mufla (40min); resfriamento fora do forno, sem ventilação (20min).

Figura 92 - Difratograma da escória sintética formada no forno de mufla (40min), resfriamento fora do forno, com ventilação forçada (6min).

Figura 93 - Difratograma da escória sintética formada no forno de mufla (40min) resfriamento dentro do forno (20h).

Figura 94 - Difratograma da escória sintética formada no forno de mufla (120min), resfriamento fora do forno, sem ventilação (20min).

Figura 95 - Difratograma da escória sintética formada no forno de mufla (120min), resfriamento fora do forno, com ventilação forçada (6min).

Figura 96 - Difratograma da escória sintética formada no forno de mufla (120min); resfriamento dentro do forno (20h).

Figura 97 - Superfície de resposta para a liberação do fósforo do pellet feed em função da temperatura e basicidade para tempo igual $10 \mathrm{~min}$.

Figura 98 - Superfície de resposta para a liberação do fósforo do pellet feed em função da temperatura e basicidade para tempo igual 30 min.

Figura 99 - Superfície de resposta para a liberação do fósforo do pellet feed em função da temperatura e basicidade para tempo igual 60 min. 
Figura 100 - Modelos ajustados a partir de dados experimentais para a liberação do fósforo do pellet feed para B2 $=0,1$

Figura 101 - Modelos ajustados a partir de dados experimentais para a liberação do fósforo do pellet feed para B2 $=0,6$.

Figura 102 - Modelos ajustados a partir de dados experimentais para a liberação do fósforo do pellet feed para B2 =0,9.

Figura 103 - Gráfico de Arrhenius Lnk pela recíproca da temperatura.

Figura 104 - Gráfico de Arrhenius Lnk pela recíproca da temperatura.

Figura 105 - Gráfico de Arrhenius Lnk pela recíproca da temperatura.

Figura 106 - Influência da temperatura sobre as velocidades iniciais para a liberação do fósforo.

Figura 107 - Influência da basicidade binária sobre a energia de ativação aparente para a liberação do fósforo.

Figura 108 - Superfícies de respostas do experimento fatorial. As tabelas dos dados simulados encontram-se no Anexo E.

Figura 109 - Correlação estatística entre os dados de liberação do fósforo experimental versus modelado.

Figura 110 - Correlação entre as constantes das equações quadráticas das superfícies de respostas das camadas inferior, intermediária e superior.

Figura 111 - Nomógrafo para obtenção de determinada liberação de fósforo na camada superior, em função da temperatura e do tempo de residência para $\mathrm{B} 2=0,1$.

Figura 112 - Nomógrafo para obtenção de determinada liberação de fósforo na camada superior, em função da temperatura e do tempo de residência para $\mathrm{B} 2=0,5$.

Figura 113 - Nomógrafo para obtenção de determinada liberação de fósforo na camada superior, em função da temperatura e do tempo de residência para $B 2=1,0$.

Figura 114 - Nomógrafo para obtenção de determinada liberação de fósforo na camada intermediária, em função da temperatura e do tempo de residência para $\mathrm{B} 2=0,1$.

Figura 115 - Nomógrafo para obtenção de determinada liberação de fósforo na camada intermediária, em função da temperatura e do tempo de residência para $B 2=0,5$.

Figura 116 - Nomógrafo para obtenção de determinada liberação de 
fósforo na camada intermediária, em função da temperatura e do tempo de residência para $\mathrm{B} 2=1,0$.

Figura 117 - Nomógrafo para obtenção de determinada liberação de fósforo na camada inferior, em função da temperatura e do tempo de residência para $\mathrm{B} 2=0,1$.

Figura 118 - Nomógrafo para obtenção de determinada liberação de fósforo na camada inferior, em função da temperatura e do tempo de residência para $\mathrm{B} 2=0,5$.

Figura 119 - Nomógrafo para obtenção de determinada liberação de fósforo na camada inferior, em função da temperatura e do tempo de residência para $\mathrm{B} 2=1,0$.

Figura 120 - Micrografia: Pelota queimada basicidade de 0,1, temperatura de $1300^{\circ} \mathrm{C}$ e tempo de residência de 6,80 min.

Figura 121 - Análise química por EDS do spectrum 5: Pelota queimada basicidade de 0,1 , temperatura de $1300^{\circ} \mathrm{C}$ e tempo de residência de 6,80 $\min$.

Figura 122 - Micrografia: Pelota queimada basicidade de 0,1, temperatura de $1300^{\circ} \mathrm{C}$ e tempo de residência de $10,23 \mathrm{~min}$.

Figura 123 - Análise química por EDS dos spectrum 1 e 2: Pelota queimada basicidade de 0,1 , temperatura de $1300^{\circ} \mathrm{C}$ e tempo de residência de 10,23 min.

Figura 124 - Micrografia: Pelota queimada basicidade de 0,1, temperatura de $1380^{\circ} \mathrm{C}$ e tempo de residência de $6,80 \mathrm{~min}$.

Figura 125 - Análise química por EDS do spectrum 8: Pelota queimada basicidade de 0,1 , temperatura de $1380^{\circ} \mathrm{C}$ e tempo de residência de 6,80 $\min$.

Figura 126 - Micrografia: Pelota queimada basicidade de 1,0, temperatura de $1300^{\circ} \mathrm{C}$ e tempo de residência de $10,23 \mathrm{~min}$.

Figura 127 - Análise química por EDS dos spectrum 1 e 4: Pelota queimada basicidade de 1,0 , temperatura de $1300^{\circ} \mathrm{C}$ e tempo de residência de 10,23 min.

Figura 128 - Micrografia: Pelota queimada basicidade de 1,0, temperatura de $1380^{\circ} \mathrm{C}$ e tempo de residência de $6,80 \mathrm{~min}$.

Figura 129 - Análise química por EDS do spectrum 2: Pelota queimada basicidade de 1,0 , temperatura de $1380^{\circ} \mathrm{C}$ e tempo de residência de 6,80 $\min$. 
Figura 130 - Micrografia: Pelota queimada basicidade de 1,0, temperatura de $1380^{\circ} \mathrm{C}$ e tempo de residência de $10,23 \mathrm{~min}$.

Figura 131 - Análise química por EDS dos spectrum 1 e 3: Pelota queimada basicidade de 1,0 , temperatura de $1380^{\circ} \mathrm{C}$ e tempo de residência de 10,23 min.

Figura 132 - Diagrama de predominância nas fases para os sistemas Fe-

P- $\mathrm{Ca}_{3}\left(\mathrm{PO}_{4}\right)_{2}-\mathrm{H}_{2}-\mathrm{H}_{2} \mathrm{O}-\mathrm{CO}-\mathrm{CO}_{2}$

Figura 133 - Montagem experimental utilizada para simulação da redução direta das pelotas.

Figura 134 - Resultado da liberação do fósforo nas pelotas e no DRI.

Figura 135 - Micrografia (aumento de 2000x): DRI basicidade de 0,1, temperatura de $1300^{\circ} \mathrm{C}$ e tempo de residência de $6,80 \mathrm{~min}$.

Figura 136 - Análise química por EDS dos spectrum 1 e 3: DRI basicidade de 0,1 , temperatura de $1300^{\circ} \mathrm{C}$ e tempo de residência de $6,80 \mathrm{~min}$.

Figura 137 - Micrografia (aumento de 500x): Pelota queimada basicidade de 0,1 , temperatura de $1300^{\circ} \mathrm{C}$ e tempo de residência de $10,23 \mathrm{~min}$.

Figura 138 - Análise química por EDS dos spectrum 1 e 4: Pelota queimada basicidade de 0,1 , temperatura de $1300^{\circ} \mathrm{C}$ e tempo de residência de 10,23 min.

Figura 139 - Micrografia (aumento de 500x): DRI basicidade de 0,5, temperatura de $1340^{\circ} \mathrm{C}$ e tempo de residência de $8,53 \mathrm{~min}$.

Figura 140 - Análise química por EDS dos spectrum 1 e 4: DRI basicidade de 0,5 , temperatura de $1340^{\circ} \mathrm{C}$ e tempo de residência de $8,53 \mathrm{~min}$.

Figura 141 - Micrografia (aumento de 2000x): DRI basicidade de 0,1, temperatura de $1300^{\circ} \mathrm{C}$ e tempo de residência de $10,23 \mathrm{~min}$.

Figura 142 - Análise química por EDS dos spectrum 1 e 3: DRI basicidade de 0,1 , temperatura de $1300^{\circ} \mathrm{C}$ e tempo de residência de $10,23 \mathrm{~min}$.

Figura 143 - Micrografia (aumento de 2000x): DRI basicidade de 1,0, temperatura de $1380^{\circ} \mathrm{C}$ e tempo de residência de $10,23 \mathrm{~min}$.

Figura 144 - Análise química por EDS do spectrum 2: DRI basicidade de 1,0 , temperatura de $1380^{\circ} \mathrm{C}$ e tempo de residência de $10,23 \mathrm{~min}$.

Figura 145 - Variação da resistência a compressão e índice de metalização em função dos ajustes das variáveis do processo de endurecimento das pelotas de redução direta.

Figura 146 - Microestrutura (aumento de 500x) das pelotas queimadas na temperatura de $1300^{\circ} \mathrm{C}$, basicidade 0,1 e nos tempos de 6,80 e 10,23 min. 
Figura 147 - Microestrutura (aumento de 500x) das pelotas queimadas na temperatura de $1380^{\circ} \mathrm{C}$, basicidade 0,1 e nos tempos de 6,80 e 10,23 min. 193 Figura 148 - Microestrutura (aumento de 500x) das pelotas queimadas na temperatura de $1300^{\circ} \mathrm{C}$, basicidade 1,0 e nos tempos de 6,80 e 10,23 min. 194 Figura 149 - Microestrutura (aumento de 500x) das pelotas queimadas na temperatura de $1380^{\circ} \mathrm{C}$, basicidade 1,0 e nos tempos de 6,80 e 10,23 min. 194 Figura 150 - Microestrutura (aumento de 500x) das pelotas queimadas na temperatura de $1340^{\circ} \mathrm{C}$, basicidade 0,5 e no tempo de $8,52 \mathrm{~min}$.

Figura 151 - Balanço de massa do fósforo livre e fluxado presente na carga metálica.

Figura 152 - Balanço de massa do fósforo da carga metálica vs carga líquida - corridas com alto potencial de desfoforação.

Figura 153 - Balanço de massa do fósforo da carga metálica vs carga líquida - corridas com baixo potencial de desfoforação.

Figura 154 - Parâmetros processo de endurecimento; temperatura versus tempo de residência para $70,5 \%$ de liberação do fósforo na pelota e consequentemente no DRI.

Figura 155 - Parâmetros processo de endurecimento; basicidade binária em função da temperatura de queima; para $70,5 \%$ de liberação do fósforo na pelota e consequentemente no DRI. 


\section{Lista de tabelas}

Tabela 1 - Especificação química da Pelota PDRMX e PBFSTD ${ }^{(18)}$. 50

Tabela 2 - Relação H/C de algumas tecnologias de redução ${ }^{(26)}$. 66

Tabela 3 - Características químicas da sucata SAMMT ${ }^{\text {(apud 22) }}$. 79

Tabela 4 - Características químicas e metalúrgicas típicas do DRI e HBI ${ }^{(37}$ e 25).

Tabela 5 - Características do ferro-gusa ${ }^{(38)}$.

Tabela 6 - Aditivos utilizados para a produção de pelotas verdes, análise química das pelotas queimadas, caracterização física das pelotas na camada superior, intermediária e inferior do pot grate e temperaturas obtidas nas três camadas e caixa de vento durante as queimas.

Tabela 7 - Resumo das técnicas instrumentais avaliadas para quantificação do fósforo nas fases minerais e escorificada.

Tabela 8 - Reagentes e Metodologias para a dissolução seletiva das gangas $(43,44,45,46,47,48,49,50$ e 51$)$.

Tabela 9 - Condições cinéticas para dissolução seletiva das gangas ${ }^{(43,44,}$ $45,46,47,48,49,50$ e 51 ).

Tabela 10- Reagentes e Metodologias para as reações sequenciais para a dissolução seletiva das gangas ${ }^{(43,44,45,46,47,48,49,50 \text { e } 51) \text {. }}$

Tabela 11 - Componentes químicos de pureza analítica para produção da pelota sintética.

Tabela 12 - Balanço de massas dos componentes para a produção da pelota sintética.

Tabela 13 - Ensaios de dissolução das gangas da pelota sintética para avaliação dos erros de medida do método químico utilizado.

Tabela 14 - Erro de calibração do ICP com padrões certificados em comparação ao erro das medidas e entre os intervalos de validade das medidas das amostras dissolução com Soda.

Tabela 15 - Erro de calibração do ICP com padrões certificados em comparação ao erro das medidas e entre os intervalos de validade das medidas das amostras dissolução com ácido Nítrico.

Tabela 16 - Erro de calibração do ICP com padrões certificados em comparação ao erro das medidas e entre os intervalos de validade das medidas das amostras dissolução com Soda e Ácido Nítrico. 
Tabela 17 - Composição da pelota RD comercial.

Tabela 18 - Composição da ganga da pelota RD comercial.

Tabela 19 - Composição da escória sintética.

Tabela 20 - Análise do Fósforo nas escórias sintéticas.

Tabela 21 - Dissolução seletiva das gangas do pellet feed com basicidade

0,1 em função da temperatura e do tempo.

Tabela 22 - Dissolução seletiva das gangas do pellet feed com basicidade 0,6 em função da temperatura e do tempo.

Tabela 23 - Dissolução seletiva das gangas do pellet feed com basicidade 0,9 em função da temperatura e do tempo.

Tabela 24 - Resultado do coeficiente de correlação linear e da energia de ativação.

Tabela 25 - Variáveis e níveis para projeto de experimento.

Tabela 26 - Planejamento de experimento interações entre variáveis.

Tabela 27 - Composição dos insumos para produção das pelotas queimadas.

Tabela 28 - Quantidade de insumos para a produção das pelotas.

Tabela 29 - Resultados do projeto de experimento.

Tabela 30 - Parâmetros ajustados a partir dos dados experimentais para as equações quadráticas, conforme tabelas no Anexo F.

Tabela 31 - Resultado da análise química por EDS: Pelota queimada basicidade de 0,1 , temperatura de $1300^{\circ} \mathrm{C}$ e tempo de residência de 6,80 $\min$;

Tabela 32 - Resultado da análise química por EDS: Pelota queimada basicidade de 0,1 , temperatura de $1300^{\circ} \mathrm{C}$ e tempo de residência de 10,23 $\min$.

Tabela 33- Resultado da análise química por EDS: Pelota queimada basicidade de 0,1 , temperatura de $1380^{\circ} \mathrm{C}$ e tempo de residência de 6,80 $\min$.

Tabela 34 - Resultado da análise química por EDS: Pelota queimada basicidade de 1,0 , temperatura de $1300^{\circ} \mathrm{C}$ e tempo de residência de 10,23 $\min$.

Tabela 35 - Resultado da análise química por EDS: Pelota queimada basicidade de 1,0 , temperatura de $1380^{\circ} \mathrm{C}$ e tempo de residência de 6,80 $\min$.

Tabela 36 - Resultado da análise química por EDS: Pelota queimada 
basicidade de 1,0 , temperatura de $1380^{\circ} \mathrm{C}$ e tempo de residência de 10,23 $\min$.

Tabela 37 - Projeto de experimento para a redução das pelotas nas condições da zona de redução de um reator Midrex.

Tabela 38 - Resultados das análises químicas obtidas das pelotas reduzidas (Figura 134 a 143 e Tabelas 41 e 42).

Tabela 39 - Resultado da análise química por EDS: DRI basicidade de 0,1, temperatura de $1300^{\circ} \mathrm{C}$ e tempo de residência de $6,80 \mathrm{~min}$.

Tabela 40 - Resultado da análise química por EDS: DRI basicidade de 0,1, temperatura de $1300^{\circ} \mathrm{C}$ e tempo de residência de $10,23 \mathrm{~min}$.

Tabela 41 - Resultado da análise química por EDS: DRI basicidade de 0,5, temperatura de $1340^{\circ} \mathrm{C}$ e tempo de residência de $8,53 \mathrm{~min}$.

Tabela 42 - Resultado da análise química por EDS: DRI basicidade de 0,1, temperatura de $1300^{\circ} \mathrm{C}$ e tempo de residência de $10,23 \mathrm{~min}$. Tabela 43 - Resultado da análise química por EDS: DRI basicidade de 1,0, temperatura de $1380^{\circ} \mathrm{C}$ e tempo de residência de $10,23 \mathrm{~min}$. Tabela 44 - Especificação do DRI, sucata e composição química do aço objetivo.

Tabela 45 - Especificação do DRI, sucata e composição química do aço objetivo.

Tabela 46 - Parâmetros para o projeto de experimentos para fusão e refino em forno semi-industrial.

Tabela 47 - Parâmetros operacionais para o FEA experimental em condições homotéticas com forno industrial.

Tabela 48 - Parâmetros operacionais para as corridas experimentais e análise química do metal.

Tabela 49 - Análise das escórias por espectroscopia infravermelho. 